\title{
Human LPLUNC1 is a secreted product of goblet cells and minor glands of the respiratory and upper aerodigestive tracts
}

\author{
Colin D. Bingle $\cdot$ Kirsty Wilson · Hayley Lunn • Frances A. Barnes • \\ Alec S. High - William A. Wallace · Doris Rassl - Michael A. Campos · \\ Manuel Ribeiro $\cdot$ Lynne Bingle
}

Accepted: 19 February 2010 / Published online: 18 March 2010

(C) The Author(s) 2010. This article is published with open access at Springerlink.com

\begin{abstract}
Long PLUNC1 (LPLUNC1, C20orf114) is a member of a family of poorly described proteins (PLUNCS) expressed in the upper respiratory tract and oral cavity, which may function in host defence. Although it is one of the most highly expressed genes in the upper airways and has been identified in sputum and nasal secretions by proteomic studies, localisation of LPLUNC1 protein has not yet been described. We developed affinity purified antibodies
\end{abstract}

Electronic supplementary material The online version of this article (doi:10.1007/s00418-010-0683-0) contains supplementary material, which is available to authorized users.

C. D. Bingle $(\bowtie) \cdot K$. Wilson $\cdot$ F. A. Barnes

Academic Unit of Respiratory Medicine,

Department of Infection and Immunity,

University of Sheffield, Sheffield S10 2JF, UK

e-mail: c.d.bingle@sheffield.ac.uk

H. Lunn · L. Bingle

Oral and Maxillofacial Pathology,

Department of Clinical Dentistry,

University of Sheffield, Sheffield, UK

\section{A. S. High}

Diagnostic Services Department,

Level 6 Medical and Dental School,

University of Leeds, Leeds, UK

W. A. Wallace

Department of Pathology,

University of Edinburgh, Edinburgh, UK

D. Rassl

Department of Pathology, Papworth Hospital,

Cambridge, UK

M. A. Campos · M. Ribeiro

Division of Pulmonary and Critical Care Medicine,

University of Miami, Miami, FL, USA and localised the protein in tissues of the human respiratory tract, oro- and nasopharynx. We have complemented these studies with analysis of LPLUNC1 expression in primary human lung cell cultures and used Western blotting to study the protein in cell culture secretions and in BAL. LPLUNC1 is a product of a population of goblet cells in the airway epithelium and nasal passages and is also present in airway submucosal glands and minor glands of the oral and nasal cavities. The protein is not expressed in peripheral lung epithelial cells. LPLUNC1 is present in bronchoalveolar lavage fluid as two glycosylated isoforms and primary airway epithelial cells produce identical proteins as they undergo mucociliary differentiation. Our results suggest that LPLUNC1 is an abundant, secreted product of goblet cells and minor mucosal glands of the respiratory tract and oral cavity and suggest that the protein functions in the complex milieu that protects the mucosal surfaces in these locations.

Keywords LPLUNC1 - Airway · Glands · Goblet cells · Immunohistochemistry $\cdot$ Innate immunity

\section{Background}

Palate lung nasal epithelium clone (PLUNC) was first described in the nasal epithelium of the mouse embryo and the trachea/bronchi of adult mice (Weston et al. 1999). We made the key observation that PLUNC belongs to a family of nine genes in a single locus on human chromosome 20q11 (Bingle and Craven 2002, 2004; Bingle et al. 2004) and showed that they make up the largest branch of a lipid transfer protein family that includes phospholipid transfer protein (PLTP), cholesterol ester transfer protein (CETP), bactericidal permeability increasing protein (BPI) and LPS-binding protein (LBP) (Bingle et al. 2004). 
Structural similarity across the PLUNC/BPI family suggests that these proteins function by binding lipid molecules (Beamer et al. 1997; Bingle and Craven 2004; Masson et al. 2009) and this led us to suggest that PLUNCs may share host defence functions with BPI and LBP (Bingle and Craven 2002). It is now generally accepted that PLUNCs fulfil a host defence function (Canny and Levy 2008) but in reality compelling functional data on members of this family has not been forthcoming. However, our genomic studies have shown that rapid evolution has produced a distinct repertoire of PLUNC genes in mammals characterised by low sequence similarity, an observation that is often found in host defence protein families (Bingle et al. 2004; Wheeler et al. 2007). The limited data which exists indicates that these genes are predominantly expressed in locations where innate defence is a major requirement, namely in the nasal, tracheal and bronchial passages as well as in major salivary glands and minor mucosal glands of the oral cavity (Weston et al. 1999; Bingle and Craven 2002; Wheeler et al. 2002; Sung et al. 2002; Di et al. 2003; LeClair et al. 2004; Bingle et al. 2004; Geetha et al. 2005; Wheeler et al. 2007). The prototypic two BPI-domain-containing protein, LPLUNC1 (or C20orf114), along with the founding family member SPLUNC1 (PLUNC), are highly expressed in the upper respiratory tract (Weston et al. 1999; Bingle and Bingle 2000; Bingle and Craven 2002; Di et al. 2003) and are attracting increased attention through their identification in many genomic and proteomic studies (Barnes et al. 2008). Importantly, LPLUNC1 and SPLUNC1 are two of the members of this family that are present in all mammals (Bingle et al. 2004; Wheeler et al. 2007). There are no published studies on the function and localisation of LPLUNC1, however, proteomic studies have identified it in nasal secretions, bronchoalveolar lavage (BAL) and sputum (Casado et al. 2005; Wu et al. 2005; Nicholas et al. 2006) and shown that it is a major secreted product of cultured tracheobronchial epithelial (TBE) cells (Candiano et al. 2007; Kesimer et al. 2009).

In the present study, we have generated and characterised antibodies specific to human LPLUNC1 and used these to carry out an extensive analysis of LPLUNC1 expression in the respiratory tract and oral cavity and have also studied the production and localisation of the protein in differentiated primary TBE cells cultured at the air-liquid interface (ALI).

\section{Materials and methods}

Generation and characterisation of human-specific LPLUNC1 antibodies

Two affinity purified, peptide-specific, polyclonal antibodies were generated in rabbits against human LPLUNC1 by
Eurogentec (Seraing, Belgium) using established methods. The peptide sequences used corresponded to amino acids, 139-154: (TIRMDTSASGPTRLV) located in the first BPI domain of LPLUNC1 (for LPLUNC1 antibody "A") and the second to amino acids, 472-484: (ASLWKPSSPVSQ) at the extreme C-terminus of the protein in the second BPI domain (for LPLUNC1 antibody "B"). These peptides were chosen so as to have minimal sequence conservation between man and mouse (Supplementary Figure S1) and no similarity with other members of the PLUNC family. Bioinformatic analysis also showed that these epitopes had no significant sequence identity with any other human proteins.

Expression clones for LPLUNC1 proteins (both mouse and human) in pcDNA5-frt-V5-His-Topo (Invitrogen) were used in the characterisation of the antibodies. Constructs were used for coupled in vitro transcription/translation (IVT) reactions (Promega) as previously described (Bingle et al. 2005, 2007) and to generate CHO cell lines stably expressing the proteins. Expression clones for SPLUNC1 and SPLUNC2, produced in the same vector, were used as controls (Bingle et al. 2005, 2009). $2 \mu \mathrm{l}$ aliquots of IVT reactions or $5 \mu \mathrm{l}$ of serum free conditioned medium from CHO cell lines stably expressing PLUNC proteins, were run on replicate SDS-PAGE gels and Western blotted using either an anti-V5 antibody (1:500 dilution) (Invitrogen) or the specific LPLUNC1 antibodies (1:2,000 dilution) and detected as described (Bingle et al. 2005, 2009).

Immunohistochemistry

The tissue used in this study was collected with ethical approval on a fully anonymous basis only and thus we have no further patient details. Serial sections $(4 \mu \mathrm{m})$ were cut from formalin-fixed and paraffin-embedded tissue as described (Bingle et al. 2005, 2006). For normal pulmonary tissues, sections were taken so as to be as representative of normal architecture as possible, although as all tissues were removed for medical reasons there was some evidence of disease in some sections. Sections from the major bronchi and peripheral lung were cut from $>15$ cases of histologically "normal" lung. The slides were stained as previously described (Bingle et al. 2005, 2007, 2009). LPLUNC1 antibodies were used at a final dilution of 1:100 (LPLUNC1A) or 1:600 (LPLUNC1B) following antigen retrieval using tri-sodium citrate in a microwave for 8 min (Bingle et al. 2007). Control sections were stained in the absence of either primary or secondary antibody. Antibodies against human SPLUNC1 (final dilution 1:300) and human mucin 5AC (MUC5AC, a gift of Dr David Thornton, University of Manchester, final dilution 1:500) were used as described (Campos et al. 2004; Bingle et al. 2007; Kirkham et al. 2008). 


\section{Cell culture, RNA extraction and RT-PCR}

Human TBE cells were cultured at an ALI as described previously (Nlend et al. 2002) using protocols approved by the local institutional review board. RNA extraction, RT-PCR and product validation was performed as described (Bingle et al. 2006, 2007) using the following primers for LPLUNC1 F 5' CCC TGC CCA ATC TAG TGA AA 3', LPLUNC1 R 5' TCA CCT TTC CCT GTG AGT CG 3' and Actin $\mathrm{F} 5^{\prime}$ CTA CAA TGA GCT GCG TGT GG 3', Actin R 5' AAG GAA GGC TGG AAG AGT GC 3'. The SPLUNC1, SLPI, Elafin and CCSP primers have been described previously (Bingle et al. 2006, 2007). RT-minus PCR reactions were run as negative controls for all experiments.

\section{Immunocytochemistry}

After harvesting apical secretions with PBS, ALI TBE culture filters were fixed with $50 \%$ acetone $/ 50 \%$ methanol for 2 min at $-20^{\circ} \mathrm{C}$, blocked with $1 \%$ BSA for $1 \mathrm{~h}$, and incubated overnight with anti-LPLUNC1 antibodies (1:500 PBS-1\% BSA) at $4^{\circ} \mathrm{C}$. All subsequent steps were done at room temperature. After washing with PBS $(3 \times)$, filters were incubated with a polyclonal goat anti-rabbit $\operatorname{IgG}$ labelled with Alexa Fluor 555 (1:5,000 PBS-1\% BSA, Molecular Probes) for $1 \mathrm{~h}$. Culture filters were sliced and incubated with either mouse anti-human MUC5AC IgG (1:100 PBS-1\% BSA, Chemicon International) or mouse anti-human acetylated tubulin IgG (1:500 PBS-1\% BSA, Sigma) for visualization of mucous or ciliated cells, respectively. In addition, some slides were incubated with goat anti-human SPLUNC1 IgG (1:100 PBS-1\% BSA, R\&D Systems). Appropriate second antibodies labelled with either Alexa Fluor 488, Alexa Fluor 555 or Cy5 (1:500 in PBS-1\% BSA, all from Molecular Probes) were added for 1 h. 4'-6-Diamidino-2-phenylindole (DAPI, 1:1,000) was added to the last wash for nuclear staining. Filters were placed in glass slides for visualization with a Zeiss LSM510 confocal laser-scanning microscope in the University of Miami Analytical Imaging Core Facility.

Western blotting of cell culture secretions and Bronchoalveolar lavage

Apical secretions were collected, every $2-3$ days, from differentiated TBE cells cultured at the ALI, by washing each well of a 12 well plate with $100 \mu$ of PBS. Pooled samples were centrifuged at $600 \times g$ to remove cellular debris and $5 \mu \mathrm{l}$ aliquots used for Western blotting as outlined above. BAL samples were obtained by instilling $60 \mathrm{ml}$ of normal saline in either the non-diseased middle lobe or lingula from subjects undergoing clinically indi- cated bronchoscopy, under a protocol approved by the University of Miami's Institutional Review Board. $15 \mu$ of BALs were subjected to Western blotting. Aliquots of ALI cell culture secretions and BAL were digested overnight with PNGase F (NEB) according to the manufacturer's instructions and Western blotted.

\section{Results}

Validation of LPLUNC1 antibodies

To study the localisation of LPLUNC1 we generated two affinity purified antibodies using unique peptide epitopes. The antibodies were validated by Western blotting with recombinant proteins (LPLUNC1, SPLUNC1 and SPLUNC2) produced both by in vitro transcription/translation and by transfected mammalian cells. An example of this validation is presented. The LPLUNC1B antibody recognised LPLUNC1 produced both in vitro and in mammalian cells (Fig. 1a) and does not cross react with SPLUNC1 or SPLUNC2 (Fig. 1b). In vitro translated LPLUNC1 protein migrates faster than that secreted by the CHO cells (Fig. 1a). The LPLUNC1A antibody reacted in a similar manner (results not shown).

LPLUNC1 is localised in a population of goblet cells in the upper airways and in submucosal and minor mucosal glands

Previously we observed expression of $L P L U N C 1$ in tissue from the nasal passages, trachea and lung (Bingle and Craven 2002), so initially used tissues from these regions for our immunohistochemical studies. Two distinct areas of staining were seen in sections from the maxillary sinus (antral) mucosa; intense staining in cells within the respiratory epithelium and also within seromucous tubules and acini of minor mucosal glands (Fig. 2a), the luminal contents of the ducts also stained. Higher magnification images show that LPLUNC1 appears to be present in epithelial cells with a characteristic "goblet cell" phenotype (Fig. 2b). Not all sinus mucosa samples contained significant goblet cells and in these cases staining of LPLUNC1 was much less intense (not shown). In tissues with squamous metaplasia we only saw significant staining in the minor glands (Fig. 2c) and it was predominantly serous cells that exhibited strong staining.

In the trachea and central bronchi the most prominent staining was seen in a population of what appeared to be surface goblet cells and in sub-mucosal glands (Fig. 2d). In a number of cases we noted the most intense staining in cells of the submucosal duct and in epithelial regions where the duct entered the airway. Staining was also seen in 

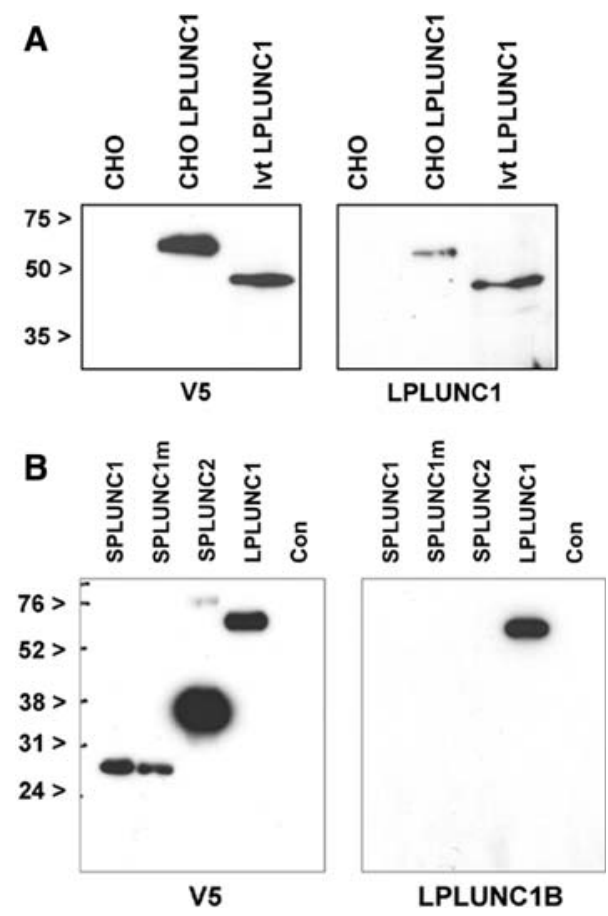

Fig. 1 Characterisation of the LPLUNC1 antibody by Western blotting. a V5-epitope tagged LPLUNC1 proteins were generated by coupled in vitro transcription and translation (Ivt-LPLUNC1) or from conditioned medium from stable $\mathrm{CHO}$ expressing cell lines $(\mathrm{CHO}$ $L P L U N C 1)$ or control medium $(\mathrm{CHO})$ as outlined in "Materials and methods". $2 \mu \mathrm{l}$ of the IVT reaction or $5 \mu$ of concentrated conditioned media was resolved on replicate $12 \%$ SDS-PAGE gels and Western blotted using the LPLUNC1B polyclonal antibody or an antibody to the V5 epitope as described. The black arrows indicate the positions of the molecular mass markers. b V5-epitope tagged PLUNC proteins were generated from conditioned medium from stable $\mathrm{CHO}$ expressing cell lines, expressing SPLUNC1 a cystine-mutant SPLUNC1 (SPLUNC1m), SPLUNC2 or LPLUNC1 or control medium (Con) as outlined in "Materials and methods". $5 \mu \mathrm{l}$ of concentrated conditioned media was resolved on replicate 12\% SDS-PAGE gels and Western blotted using the LPLUNC1B polyclonal antibody or an antibody to the V5 epitope as described. The black arrows indicate the positions of the molecular mass markers

epithelial cells of smaller airways (those without cartilage and submucosal glands, Fig. 2e, f). Importantly LPLUNC1 staining was never seen in the alveolar epithelium (Fig. 2f) nor were we able to detect specific staining in endothelial cells or in inflammatory cells, including alveolar macrophages (results not shown). To ensure specificity of the antibodies we stained closely cut sections with both antibodies. They both stained cells of the seromucous tubules in submucosal glands (Fig. $2 \mathrm{~h}$, i) suggesting that they both recognise the same protein. Mucous cells in the airway submucosal glands did not stain. Additional antibodies to SPLUNC2 generated and purified at the same time (Bingle et al. 2009) as the LPLUNC1 antibodies failed to show any staining in the lung sections (results not shown) and sections stained without the addition of primary or secondary antibodies were also negative for staining (results not shown) further supporting our belief that these antibodies are valid reagents for the specific detection of human LPLUNC1.

Localisation of LPLUNC1 was directly compared with the prototypic family member, SPLUNC1, in the respiratory tract; the two proteins are not co-localised (Fig. 3). LPLUNC1 stained a goblet cell population in the trachea and smaller airways (Fig. 3a, c) but these were negative for SPLUNC1 (Fig. 3b, d). In airway submucosal glands a similar, essentially mutually exclusive localisation pattern was seen (Fig. 3e, f), with staining of serous demilunes of the gland by anti-LPLUNC1 (black arrow, Fig. 3e) but not SPLUNC1, which only stained mucous tubules within the gland (red arrow, Fig. 3f). Our results do, however, suggest that a few cells in submucosal gland ducts may exhibit co-localisation of both proteins (Fig. 3e, f). We also stained sections with MUC5A/C to confirm that the LPLUNC1 positive cells were goblet cells (Fig. 4). However, although MUC5A/C and LPUNC1 were present in similar locations in the airways and in submucosal glands not all MUC5A/C expressing cells were positive for LPLUNC1 suggesting that it is not a surrogate marker for airway goblet cells.

As mouse Lpluncl is highly expressed in minor glands of the tongue (Leclair et al. 2004) we extended our studies to minor salivary glands of the oral cavity (Fig. 5). The keratinised epithelial surface of the tongue and the muscle was uniformly negative for LPLUNC1 (results not shown). However, in the posterior portion of tongue some of the minor glands demonstrated strong LPLUNC1 staining in the seromucous acini and within ductular cells (Fig. 5a), whereas others (more mucous-like) did not (Fig. 5b). Minor glands of the vallecular region of the tongue, associated with tonsil, also stained with LPLUNC1 (Fig. 5c). The majority of the tonsil tissue, including tonsillar crypts or germinal centres did not stain (results not shown). Interestingly, in minor glands associated with the tonsil we saw co-localisation with SPLUNC1 (Fig. 5d). In all cases the staining pattern was identical irrespective of which LPLUNC1 antibody was used (results not shown).

LPLUNC1 is secreted from goblet cells in differentiated TBE cell cultures as a glycosylated protein

On the basis of the in vivo localisation of LPLUNC1, we used primary human TBE cells to investigate the production and secretion of LPLUNC1. Array studies have previously suggested that LPLUNC1 mRNA is abundantly expressed in these cells (Ross et al. 2007). LPLUNC1 mRNA expression was readily detected in TBE cells directly harvested from healthy donor lungs (Fig. 6a, lane $\mathrm{H})$ but was lost as the cells de-differentiated in submerged cell culture (P1 and P2), as confirmed by loss of CCSP, a marker of differentiated bronchiolar cells, and the related 
Fig. 2 Distribution of LPLUNC1 in the respiratory tract. Immunohistochemistry for LPLUNC1 was performed with the LPLUNC1B antibody as described in "Materials and methods". Sections show staining in samples of nasal antral mucosa $(\mathbf{a}-\mathbf{c})$, trachea (d), bronchial airways (e) and bronchiolar epithelium (f). Serial sections of trachea were stained with both antibodies, LPLUNC1A (g) and LPLUNC1B (h). The original magnifications of the images were $\approx \times 100(\mathbf{a}, \mathbf{c}, \mathbf{d}), \times 200$ (e-h) and $\times 400$ (b)

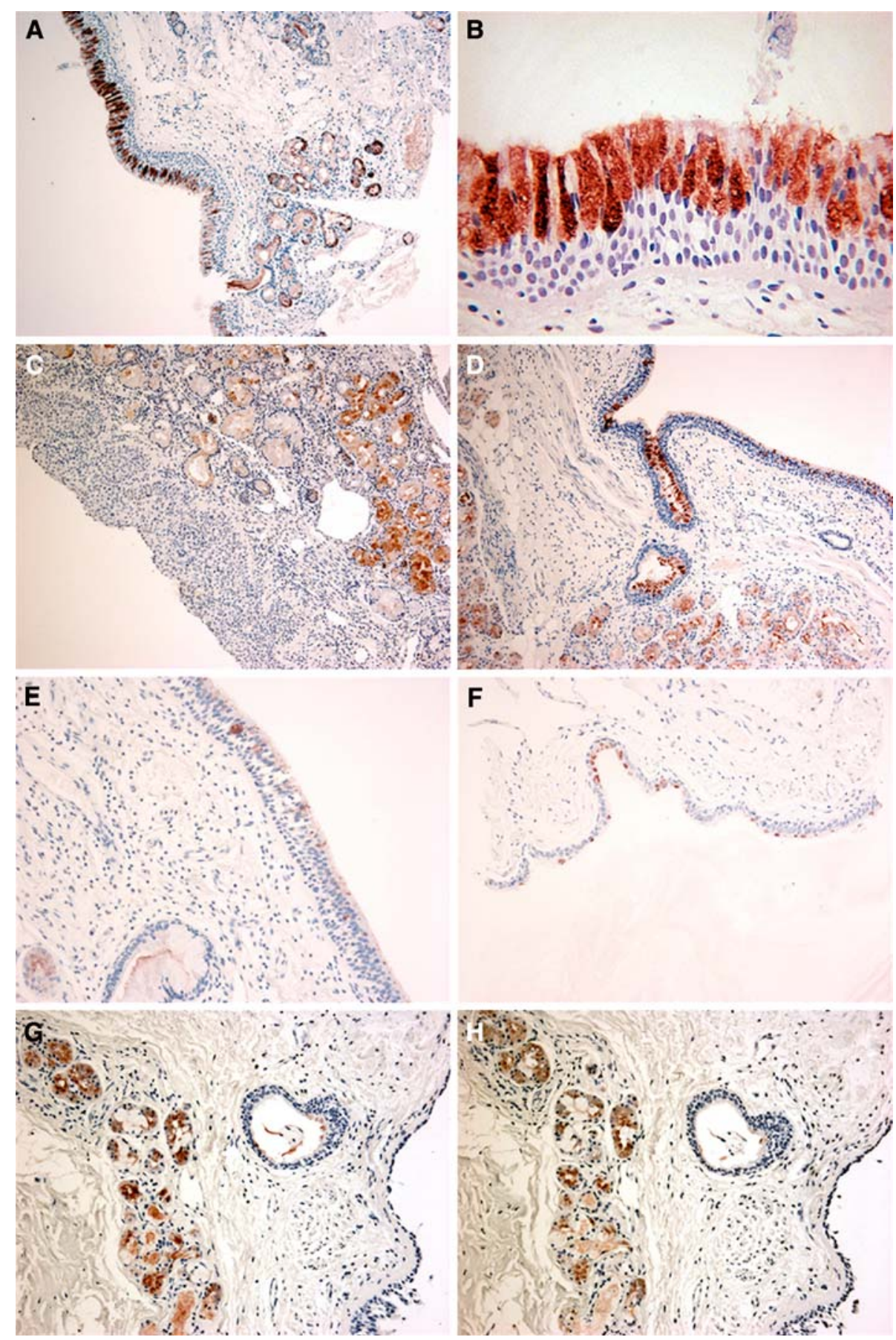

pulmonary protein SPLUNC1. When the cells were placed at an ALI they re-differentiated, demonstrated by the visual appearance of cilia (results not shown) and re-expression of CCSP, and the expression of LPLUNC1 (and SPLUNC1) increased (Fig. 6a, lane d14). Removal of retinoic acid from the culture medium of fully differentiated cells gradually results in the development of a squamous phenotype (Yoon et al. 1997). This was confirmed by the induction of the squamous cell marker elafin (Bingle et al. 2006) and was associated with a progressive loss of LPLUNC1 expression that mirrors the previously described loss of SPLUNC1 (Bingle et al. 2007; Fig. 6b). Expression was not completely lost after 18 days of RA withdrawal suggesting that the phenotypic alteration was not complete at this time. In keeping with the localisation of LPLUNC1 in vivo we were also unable to detect expression or secretion of LPLUNC1 in primary alveolar epithelial cells (results not shown).

Secretion of LPLUNC from ALI cells has not previously been studied. We sampled the mucous secretions from the surface of the epithelial cell cultures as they underwent the 
Fig. 3 LPLUNC1 and SPL-

UNC1 do not co-localise in the respiratory tract. Immunohistochemistry was performed as described in "Materials and methods" for LPLUNC1 (a-e) and SPLUNC1 $(\mathbf{b}, \mathbf{d}, \mathbf{f})$. Sections show staining in serial samples of airways (a-d) and in an airway submucosal gland $(\mathbf{e}, \mathbf{f})$. The black arrow in e shows a serous demilune that is positive for LPLUNC1 whereas the red arrow in $\mathbf{f}$ points to the same group of cells that is negative for SPLUNC1. The original magnifications of the images were $\times 200(\mathbf{a}, \mathbf{b})$ and $\times 400(\mathbf{c}-\mathbf{f})$
Fig. 4 LPLUNC1 and MUC5A/C do not always co-localise in the respiratory tract. Immunohistochemistry was performed as described in "Materials and methods" for LPLUNC1 (a, c) and MUC5A/C $(\mathbf{b}, \mathbf{d})$. Sections show staining in serial samples of airways (a, $\mathbf{d})$ and in an airway submucosal gland (c, d). The original magnifications of the images were $\times 200(\mathbf{a}, \mathbf{b})$ and $\times 400(\mathbf{c}, \mathbf{d})$
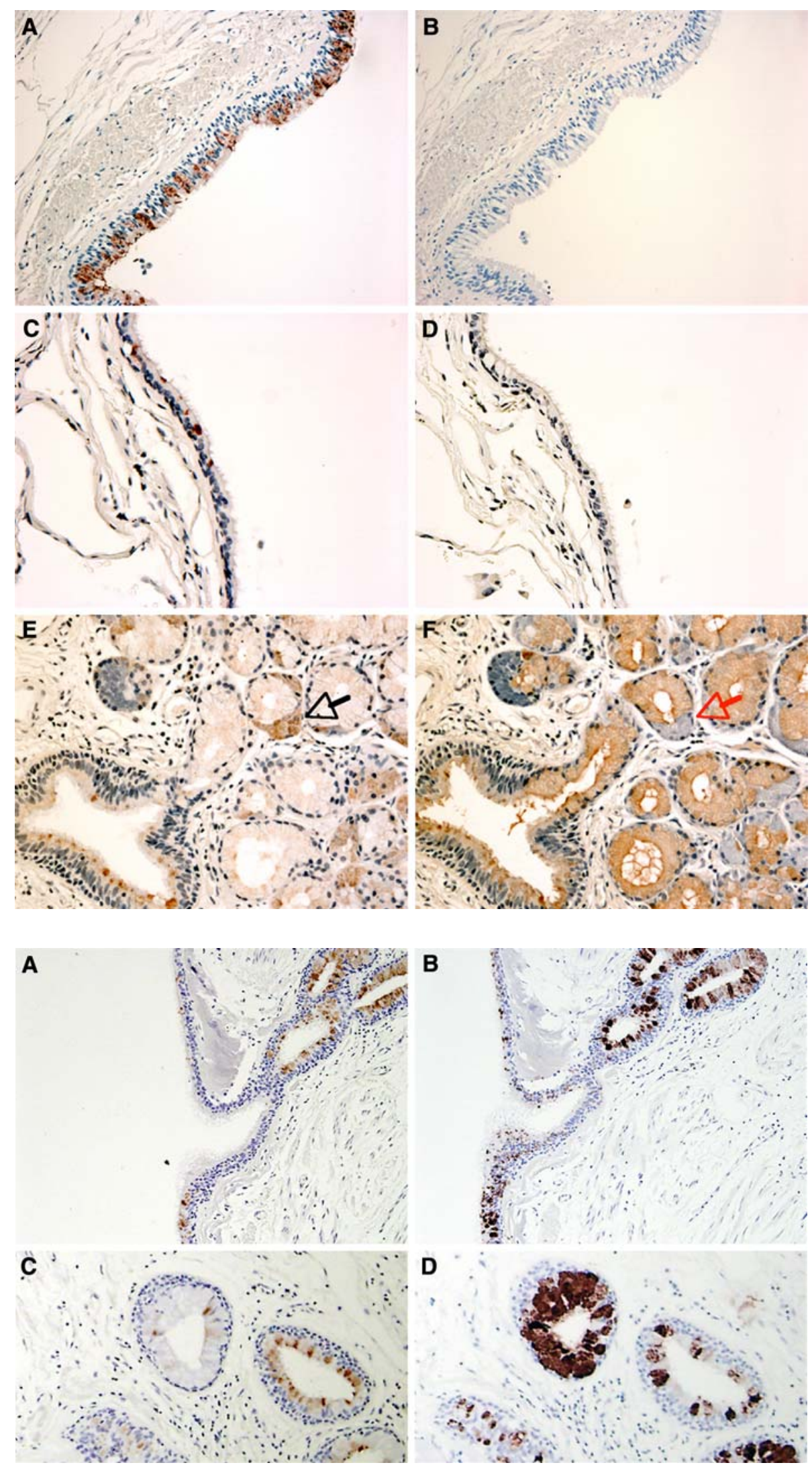
Fig. 5 Distribution of LPLUNC1 in minor glands of the oral cavity. Immunohistochemistry for LPLUNC1 and SPLUNC1 was performed as described in "Materials and methods". Sections show staining in a seromucous gland of in the tongue (a) but no staining in a minor mucus gland in the proximal tongue (b). Serial sections of minor glands surrounding the palatine tonsils show that both LPLUNC1 (c) and SPLUNC1 (d) are positive in the same region. The original magnifications of the images were $\times 200(\mathbf{a}, \mathbf{b})$ and $\times 400(\mathbf{c}, \mathbf{d})$
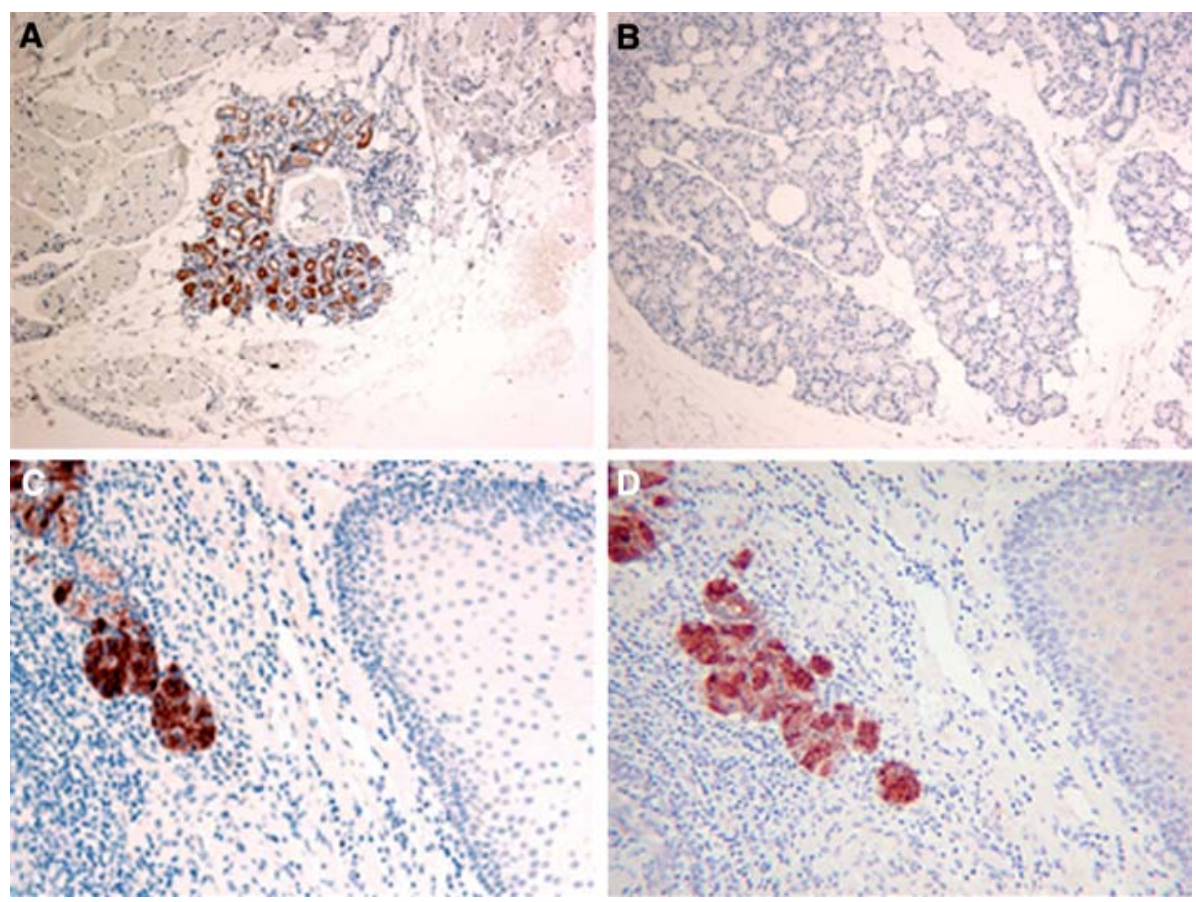

process of differentiation. LPLUNC1 protein was readily detectable in the ALI secretions as two distinct immunoreactive products (Fig. 7a). Levels of protein appeared to increase as the cells differentiated; these results were confirmed in a second set of samples from a different donor. Both protein bands were of greater size than the predicted size, similar to the protein produced by $\mathrm{CHO}$ cells (Fig. 1). This suggested that the protein undergoes some form of post-translational modification and to investigate this we carried out de-glycosylation studies using PNGaseF (which hydrolyses most $\mathrm{N}$-glycan chains). Both immunoreactive bands reduced in size following PNGase treatment suggesting that LPLUNC1 secreted by ALI cells is $N$-glycosylated (Fig. 7b). BAL treated with PNGase demonstrated similar immunoreactive LPLUNC1 bands, suggesting that the protein product of the differentiated ALI cells is glycosylated in the same way as that secreted into the airways in vivo (Fig. 7b). Identical results were also seen when replicate blots from both studies were Western blotted using the LPLUNC1A antibody (results not shown). Importantly, we also failed to show that LPLUNC1 was subjected to any further proteolytic cleavage in either sample as no additional, smaller, immunoreactive bands were seen (Fig. 7a, b).

Immunocytochemistry was used to identify the specific site of production of LPLUNC1 in TBE cell cultures. This indicated that LPLUNC1 is present in a population of nonciliated cells (Fig. 8a) whilst the population of cells that secrete SPLUNC1 is greater and for the most part different from the cells that secrete LPLUNC1. LPLUNC1 was again shown to be present in a subpopulation of MUC5AC staining cells (Fig. 8b). Importantly this analysis suggests that not all LPLUNC1 expressing cells stain with MUC5AC and vice versa.

\section{Discussion}

Since our original description of LPLUNC1 as the prototypic two BPI-domain-containing PLUNC family member (Bingle and Craven 2002), no studies have addressed the localisation or secretion of the protein. In the present study, we used highly specific antibodies to localise expression of LPLUNC1 in the upper respiratory tract, nasal and oral cavities. We took great care to ensure that the antibodies recognise only LPLUNC1 by choosing peptides that had no sequence conservation with other PLUNC family members and that are not conserved in orthologues from rodent species (Bingle and Craven 2002; Bingle et al. 2004). Furthermore these epitopes are not present in any other mouse protein. The fact that both antibodies stained proteins in the same cells in the tissue sections (Fig. 2) and recognised the same protein bands in Western blotting of ALI secretions and BAL fluid, lend further support of our suggestion that they are recognising human LPLUNC1 specifically. The antibodies indicate that the protein is abundantly expressed in a population of goblet cells in the upper respiratory tract and that the protein is strongly expressed in airway submucosal glands and a range of minor glands present in the oral cavity and nasopharynx. Our Western blotting studies, which identified the protein in BAL fluid, provide strong evidence for secretion of LPLUNC1 into mucosal lining 


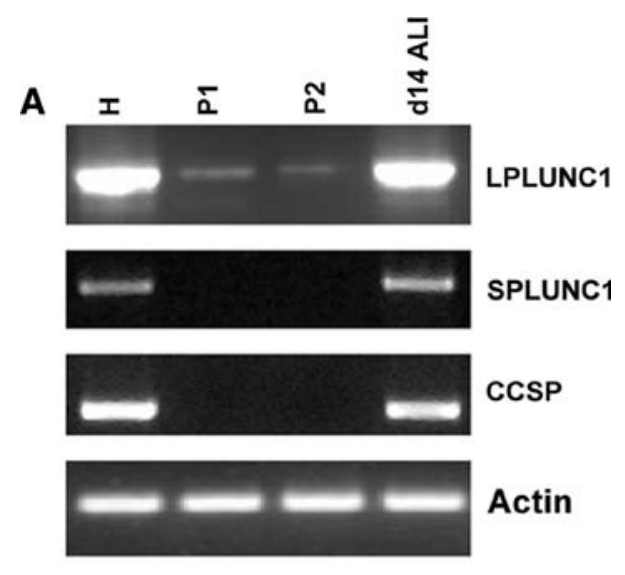

B
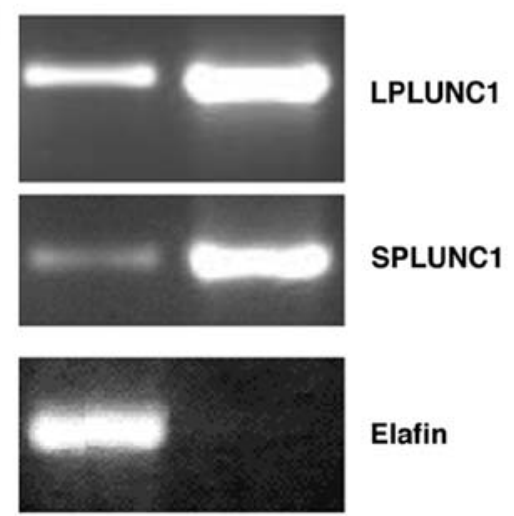

Elafin

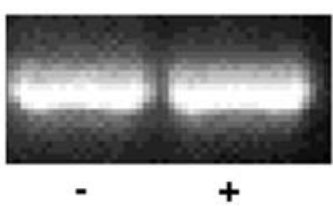

SLPI

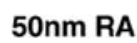

Fig. 6 LPLUNC1 is expressed in primary tracheal cells and cells differentiated at the ALI. a Expression of LPLUNC1 was studied by PCR using freshly harvested human tracheal cells $(H)$ and samples taken from the cultures at two stages $(P 1, P 2)$ as the cells were established at an air-liquid interface $(A L I)$. Expression of SPLUNC1, the non-ciliated tracheal cell marker CCSP and actin (as a PCR control) was also monitored in the same samples. b Expression of LPLUNC1 was studied by PCR in samples of primary tracheobronchial epithelial cells during retinoic acid depletion and the subsequent loss of the differentiated phenotype. ALI cells were established using standard growth conditions in medium containing $50 \mathrm{nM}$ all trans retinoic acid $(R A)$. After 14 days in culture RA was removed from the medium of one group of cells and culture was continued for an additional 18 days. Expression of $L P L U N C 1$ and SPLUNC1 was investigated by RT-PCR with exon spanning primer pairs as described in "Materials and methods" with primers to SLPI and elafin serving as a positive controls. RT-negative PCR reactions were run for each experiment and representative RCR products were cloned and sequenced for confirmation. The data in both panels represents one of three sets of experiments performed with cells from different donors

fluids and also supports a number of proteomic studies that have reported the protein in BAL, sputum and in nasal secretions (Casado et al. 2005; Wu et al. 2005; Nicholas et al. 2006; Candiano et al. 2007; Kesimer et al. 2009).

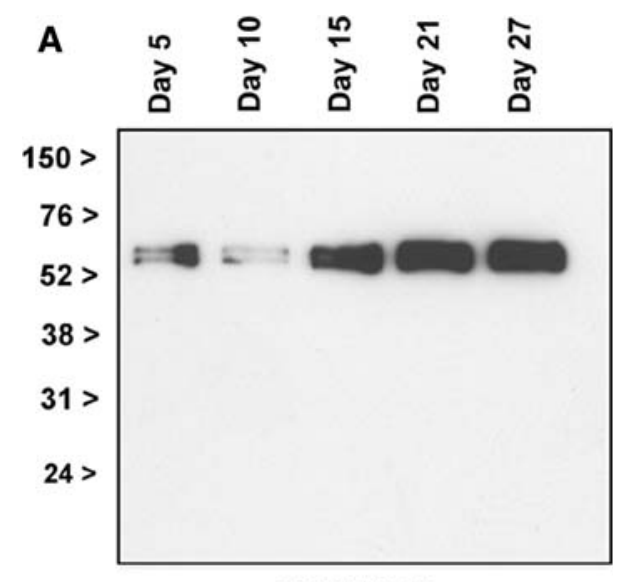

LPLUNC1B

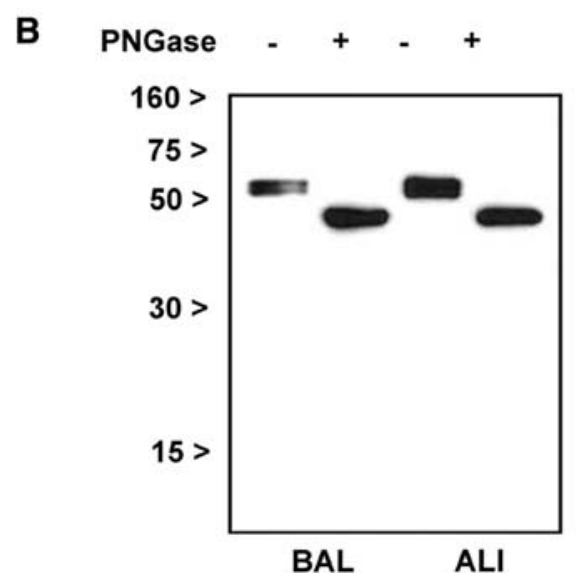

Fig. 7 LPLUNC1 is secreted into the apical fluid as a glycosylated protein identical to that found in BAL fluid. a Secretion of LPLUNC1 into apical secretions harvested from ALI cell cultures was shown by Western blotting using the LPLUNC1B antibody. Samples were harvested from the cells every $2-3$ days. The positions of the molecular mass markers are indicated by the black arrows. The data is representative of two different experiments. b Deglycosylation studies were performed using BAL fluid and ALI secretions as described in "Materials and methods". The resultant reaction products were subjected to Western blotting and detected with the LPLUNC1B antibody. The positions of the molecular mass markers are indicated by the black arrows

Although LPLUNC1 appears to be present in a population of goblet cells in the airways in these non-diseased samples it is not present in all goblet cells and is most commonly seen in those that are closely associated with the junction of the submucosal gland duct and within the duct itself. Thus, LPLUNC1 is not a surrogate marker for airway goblet cells especially as in the normal airways there are clearly a significant number of MUC5AC containing cells that are negative for LPLUNC1. It is possible that the lack of staining seen in some goblet cells may reflect the fact that the protein has been secreted into the airway lumen. Further studies are required to identify if these LPLUNC1 positive goblet cells exhibit any additional unique characteristics. Mouse lpluncl RNA has been shown to be 


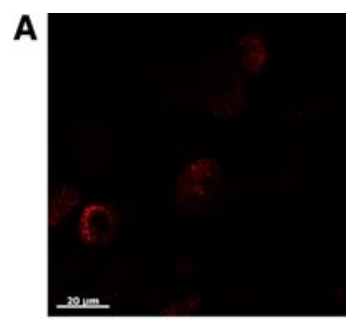

LPLUNC1

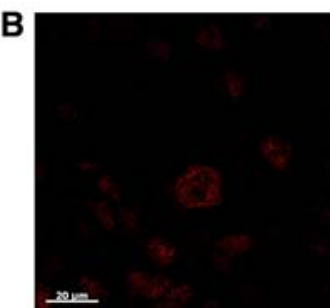

LPLUNC1

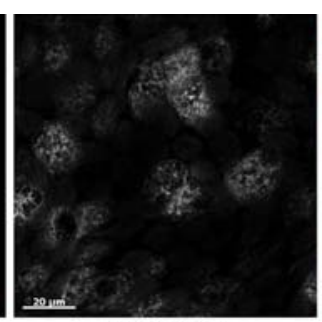

SPLUNC1

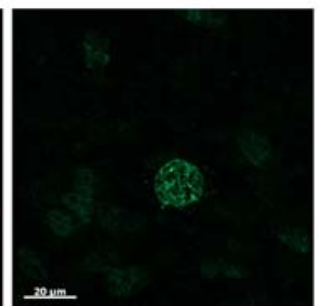

MUC 5ac

Fig. 8 LPLUNC1 is localised in non-ciliated MUC5AC positive cells in TBE ALI cell cultures. Confocal IF microscopy was performed on differentiated ALI cultures as described in "Materials and methods" for LPLUNC1, SPLUNC1, tubulin and MUC5A/C as described. a LPLUNC1 and SPLUNC1 are localised in non-ciliated cells. Ciliated cells

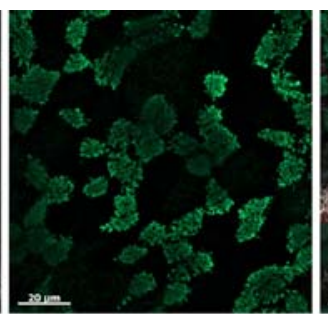

Acetilated Tubulin

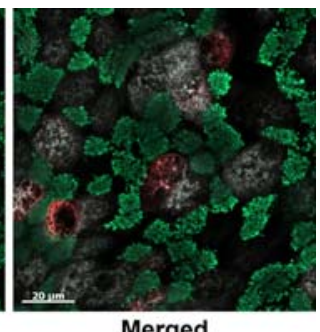

Merged

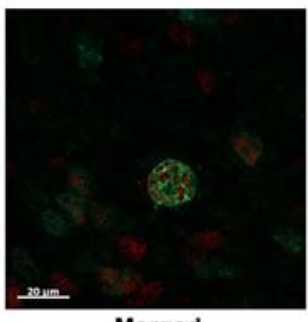

Merged

were identified with IgG anti-acetylated tubulin present in ciliary structures. The population of SPLUNC1-positive cells is more abundant than LPLUNC1 positive cells. b LPLUNC1 is present in some MUC5AC positive cells. All pictures were taken with a Zeiss LSM510 confocal microscope, at $\times 40$ with a $\times 2$ digital zoom

The mechanisms that govern expression of PLUNCs have not been elucidated, in part because of the lack of suitable cell lines in which to perform these studies. We have reported SPLUNC1 NCI-H647 cells (Bingle and Bingle 2000), but have been unable to find an established cell line that supports expression of LPLUNC1 (results not shown). Our analysis of the ALI TBE cells suggests that this model system may be a useful one in which to uncover regulatory mechanisms as they express both LPLUNC1 and SPLUNC1 and levels of gene expression can be modulated by the differentiation status of the cultures. The ALI cultures further mimicked the situation in the airways in vivo as LPLUNC1 was found in a population of 'goblet' cells, as judged by the co-expression of MUC5A/C, but expression of the two markers was not always seen in the same cells. However, in contrast to this, in vitro expression of LPLUNC1 was seen in a subpopulation of cells that also produce SPLUNC1 suggesting that this culture model may support some uncoupling of gene expression not seen in "normal" airways. SPLUNC1 was still seen in more cells than LPLUNC1. These studies confirm that ALI TBE cells maybe useful tools in which to study the regulation of LPLUNC1 and SPLUNC1 gene expression.

The LPLUNC1 secreted by TBE cells was glycosylated in a manner similar to that found in BAL samples. $\mathrm{N}$ glycosylated isoforms of LPLUNC1 have also been described in saliva (Ramachandra et al. 2008) and it seems likely that this post-translational modification, and thus the glycosylation status, is functionally important for the biological activity of LPLUNC1. Previous studies have also 
shown that other PLUNCs, including both SPLUNC1 and the salivary enriched protein, SPLUNC2/psp, are also subjected to significant post-translational modifications (Mirels et al. 1998; Ghafouri et al. 2004; Bingle et al. 2009) suggesting that it is a common feature of this family of proteins. Our Western blotting studies also suggest that LPLUNC1 is not subject of significant proteolytic processing in normal airways secretions. We could not detect any smaller proteolytic fragments either the ALI secretions or the BAL fluid when samples were probed with either antibody. It remains to be seen if a similar situation is seen in samples from lung disease.

Our studies suggest that LPLUNC1 is expressed in a goblet cell population and thus it seems likely that alterations of LPLUNC1 localisation and production may be found in lung diseases associated with increase numbers of goblet cells. This suggestion is further supported by the observation that Lpluncl is elevated in multiple array studies of mouse models of lung diseases (Barnes et al. 2008) in which goblet cell number are known to be increased. We have previously reported an increase in SPLUNC1 protein production by airway epithelial cells in severe cystic fibrosis (Bingle et al. 2007) due to a phenotypic alteration in the airways in such patients and are presently evaluating LPUNC1 expression in this and a series of other human disease sample sets.

In summary, we have localised LPLUNC1 to a subset of goblet cells within the airways, in the submucosal glands of the upper airways, as well as in minor glands in the nose, sinuses, posterior tongue and tonsil. LPLUNC1 is present in BAL fluid as a glycoprotein and we have shown that expression and secretion of the protein is increased in TBE cells as they undergo mucociliary differentiation in culture. Although the function of LPLUNC1 remains to be resolved, our results suggest that the protein functions in the complex milieu that protects the mucosal surfaces in these locations.

Acknowledgments This work was funded by the Wellcome Trust. We are grateful to Moira Whyte and Thais Mauad for helpful discussions and advice on this manuscript. The MUC5A/C antibody was a gift from David Thornton, University of Manchester, UK.

Open Access This article is distributed under the terms of the Creative Commons Attribution Noncommercial License which permits any noncommercial use, distribution, and reproduction in any medium, provided the original author(s) and source are credited.

\section{References}

Barnes FA, Bingle L, Bingle CD (2008) Pulmonary genomics, proteomics and PLUNCs. Am J Respir Cell Mol Biol 38:377-379

Beamer LJ, Carroll SF, Eisenberg D (1997) Crystal structure of human BPI and two bound phospholipids at 2.4 angstrom resolution. Science 276:1861-1864
Bingle CD, Bingle L (2000) Characterisation of the human plunc gene, a gene product with an upper airways and nasopharyngeal restricted expression pattern. Biochim Biophys Acta 1493:363-367

Bingle CD, Craven CJ (2002) PLUNC: a novel family of candidate host defence proteins expressed in the upper airways and nasopharynx. Hum Mol Genet 11:937-943

Bingle CD, Craven CJ (2004) Meet the relatives: a family of BPI and LBP-related proteins. Trends Immunol 25:53-55

Bingle CD, LeClair EE, Havard S, Bingle L, Gillingham P, Craven CJ (2004) Phylogenetic and evolutionary analysis of the PLUNC gene family. Protein Sci 13:422-430

Bingle L, Cross SS, High AS, Wallace WA, Devine DA, Havard S, Campos MA, Bingle CD (2005) SPLUNC1 (PLUNC) is expressed in glandular tissues of the respiratory tract and in cancers with a glandular phenotype. J Pathol 205:491-497

Bingle L, Cross SS, High AS, Wallace WA, Rassl D, Yuan G, Hellstrom I, Campos MA, Bingle CD (2006) WFDC2 (HE4): a potential role in the innate immunity of the oral cavity and respiratory tract and the development of adenocarcinomas of the lung. Respir Res 7:61

Bingle L, Barnes FA, Cross SC, Rassl D, Wallace WA, Campos MA, Bingle CD (2007) Differential epithelial expression of the putative innate immune molecule, SPLUNC1 in cystic fibrosis. Respir Res 8:79

Bingle L, Barnes FA, Lunn H, Musa M, Webster S, Douglas CWI, Cross SS, High AS, Bingle CD (2009) Characterisation and expression of SPLUNC2, the human orthologue of rodent parotid secretory protein. Histochem Cell Biol 132:339-349

Campos MA, Abreu AR, Nlend MC, Cobas MA, Conner GE, Whitney PL (2004) Purification and characterization of PLUNC from human tracheobronchial secretions. Am J Respir Cell Mol Biol 30:184-192

Candiano G, Bruschi M, Pedemonte N, Musante L, Ravazzolo R, Liberatori S, Bini L, Galietta LJ, Zegarra-Moran O (2007) Proteomic analysis of the airway surface liquid: modulation by proinflammatory cytokines. Am J Physiol Lung Cell Mol Physiol 292:L185-L198

Canny G, Levy O (2008) Bactericidal/permeability-increasing protein (BPI) and BPI homologs at mucosal sites. Trends Immunol 29:541-547

Casado B, Pannell LK, Iadarola P, Baraniuk JN (2005) Identification of human nasal mucous proteins using proteomics. Proteomics 5:2949-2959

Di Y-P, Harper R, Zhao Y, Pahlavan N, Finkbeiner W, Wu R (2003) Molecular cloning and characterization of spurt, a human novel gene that is retinoic acid-inducible and encodes a secretory protein specific in upper respiratory tracts. J Biol Chem 278:1165-1173

Flach CF, Qadri F, Bhuiyan TR, Alam NH, Jennische E, Lönnroth I, Holmgren J (2007) Broad up-regulation of innate defense factors during acute cholera. Infect Immun 75:2343-2350

Geetha C, Venkatesh SG, Bingle L, Bingle CD, Gorr SU (2005) Design and validation of anti-inflammatory peptides from human parotid secretory protein. J Dent Res 84:149-153

Ghafouri B, Kihlström E, Tagesson C, Lindahl M (2004) PLUNC in human nasal lavage fluid: multiple isoforms that bind to lipopolysaccharide. Biochim Biophys Acta 1699:57-63

Kesimer M, Kirkham S, Pickles RJ, Henderson AG, Alexis NE, DeMaria G, Knight D, Thornton DJ, Sheehan JK (2009) Tracheobronchial air-liquid interface cell culture: a model for innate mucosal defense of the upper airways? Am J Physiol Lung Cell Mol Physiol 296:L92-L100

Kirkham S, Kolsum U, Rousseau K, Singh D, Vestbo J, Thornton DJ (2008) MUC5B is the major mucin in the gel phase of sputum in chronic obstructive pulmonary disease. Am J Respir Crit Care Med 178:1033-1039 
LeClair EE, Nomellini V, Bahena M, Singleton V, Bingle L, Craven CJ, Bingle CD (2004) Cloning and expression of a mouse member of the PLUNC protein family exclusively expressed in tongue epithelium. Genomics 83:658-666

Masson D, Jiang X-C, Lagrost L, Tall AR (2009) The role of plasma lipid transfer proteins in lipoprotein metabolism and atherogenesis. J Lipid Res 50(Suppl):S201-S206

Mirels L, Miranda AJ, Ball WD (1998) Characterization of the rat salivary-gland B1-immunoreactive proteins. Biochem J 330:437-444

Nicholas B, Skipp P, Mould R, Rennard S, Davies DE, O’Connor CD, Djukanovic R (2006) Shotgun proteomic analysis of humaninduced sputum. Proteomics 6:4390-4401

Nlend MC, Bookman RJ, Conner GE, Salathe M (2002) Regulator of G-protein signaling protein 2 modulates purinergic calcium and ciliary beat frequency responses in airway epithelia. Am J Respir Cell Mol Biol 27:436-445

Ramachandra P, Boontheung P, Pang E, Yan W, Wong DT, Loo JA (2008) Comparison of N-linked glycoproteins in human whole saliva, parotid, submandibular, and sublingual glandular secretions identified using hydrazide chemistry and mass spectrometry. Clin Proteomics 4:80-104

Ross AJ, Dailey LA, Brighton LE, Devlin RB (2007) Transcriptional profiling of mucociliary differentiation in human airway epithelial cells. Am J Respir Cell Mol Biol 37:169-185

Sung YK, Moon C, Yoo JY, Moon C, Pearse D, Pevsner J, Ronnett GV (2002) Plunc, a member of the secretory gland protein family, is up-regulated in nasal respiratory epithelium after olfactory bulbectomy. J Biol Chem 277:12762-12769

Weston WM, LeClair EE, Trzyna W, McHugh KM, Nugent P, Lafferty CM, Ma L, Tuan RS, Greene RM (1999) Differential display identification of plunc, a novel gene expressed in embryonic palate, nasal epithelium, and adult lung. J Biol Chem 274:13698-13703

Wheeler TT, Haigh BJ, McCracken JY, Wilkins RJ, Morris CA, Grigor MR (2002) The BSP30 salivary proteins from cattle, LUNX/ PLUNC and von Ebner's minor salivary gland protein are members of the PSP/LBP superfamily of proteins. Biochim Biophys Acta 1579:92-100

Wheeler TT, Hood KA, Maqbool N, McEwan JC, Bingle CD, Zhao S (2007) Expansion of the bactericidal/permeability increasing-like (BPI-like) protein locus in cattle. BMC Genomics 8:75

Wu J, Kobayashi M, Sousa EA, Liu W, Cai J, Goldman SJ, Dorner AJ, Projan SJ, Kavuru MS, Qiu Y, Thomassen MJ (2005) Differential proteomic analysis of bronchoalveolar lavage fluid in asthmatics following segmental antigen challenge. Mol Cell Proteomics 4:1251-1264

Yoon JH, Gray T, Guzman K, Koo JS, Nettesheim P (1997) Regulation of the secretory phenotype of human airway epithelium by retinoic acid, triiodothyronine, and extracellular matrix. Am J Respir Cell Mol Biol 16:724-731 